\title{
Comprehending Care in a Medical Home: A Usual Source of Care and Patient Perceptions about Healthcare Communication
}

\author{
Jennifer E. DeVoe, MD, DPhil, Lorraine S. Wallace, PhD, Nancy Pandhi, MD, MPH, \\ Rachel Solotaroff, $M D$, and George E. Fryer, Jr, PhD
}

Objective: To examine whether having a usual source of care (USC) is associated with positive patient perceptions of health care communication and to identify demographic factors among patients with a USC that are independently associated with differing reports of how patients perceive their involvement in health care decision making.

Methods: Cross-sectional analyses of nationally representative data from the 2002 Medical Expenditure Panel Survey. Among adults with a health care visit in the past year $(n=\sim 16,700)$, we measured independent associations between having a USC and patient perceptions of health care communication. Second, among respondents with a USC $(n=\sim 18,000)$, we assessed the independent association between various demographic factors and indicators of patients' perceptions of their autonomy in making health care decisions.

Results: Approximately $78 \%$ of adults in the United States reported having a USC. Those with a USC were more likely to report that providers always listened to them, always explained things clearly, always showed respect, and always spent enough time with them. Patients who perceived higher levels of decision-making autonomy were non-Hispanic, had health insurance coverage, lived in rural areas, and had higher incomes.

Conclusions: Patients with a USC were more likely to perceive positive health care interactions. Certain demographic factors among the subgroups of Medical Expenditure Panel Survey respondents with a USC were associated with patient perceptions of greater decision-making autonomy. Efforts to ensure universal access to a USC must be partnered with broader awareness and training of USC providers to engage patients from various demographic backgrounds equally when making health care decisions at the point of care. ( $\mathrm{J}$ Am Board Fam Med 2008;21:441-450.)

For many patients, navigating the health care system in the United States can be daunting. With the increasing complexity of medical technology and an explosion of media messages about pharmaceutical products, it is sometimes difficult to compre-

This article was externally peer reviewed.

Submitted 7 March 2008; revised 3 June 2008; accepted 10 June 2008 .

From the Department of Family Medicine, University of Tennessee Graduate School of Medicine, Knoxville (LSW); the Department of Family Medicine, University of Wisconsin-Madison School of Medicine and Public Health (NP); the Department of Internal Medicine (RS) and the Department of Internal Medicine (JED), Oregon Health and Science University, Portland; and the Department of Pediatrics, New York University, New York (GEF).

Funding: Dr. DeVoe's time on this project was partially supported by grant numbers 5 F32 HS014645 and 1 K08 HS16181 from the Agency for Healthcare Research and Quality. hend care. The ability to understand professional recommendations and to communicate with clinicians is important to the receipt of good quality health care services, and it impacts patient satisfaction. ${ }^{1,2}$ In turn, establishing good lines of commu-

Prior presentation: Preliminary results from this study were presented at the North American Primary Care Research Group Annual Meeting, Tucson, Arizona, October 15-19, 2006.

Conflict of interest: none declared.

Corresponding author: Jennifer E. DeVoe, MD, DPhil, Department of Family Medicine, Oregon Health and Science University, 3181 Sam Jackson Park Road, Mailcode: FM, Portland, OR 97239 (E-mail: devoej@ohsu.edu).

$$
\begin{aligned}
& \text { See Related Commentary on } \\
& \text { Page } 370 .
\end{aligned}
$$


nication can lead to better patient-reported health status and health outcomes. ${ }^{3-5}$

Establishing care with a specific person or at a familiar primary care site is also associated with several beneficial outcomes, including higher receipt of recommended preventive health care services, decreased inappropriate use of the emergency department, shortened lengths of stay in the hospital, and improved health status. ${ }^{6-20}$ Conversely, when people lack a regular source of care their access to necessary services is reduced, ${ }^{21-26}$ which may result in poorer health outcomes. ${ }^{27}$ Lack of continuity disproportionately affects certain groups for whom a continuity relationship is especially important, such as those with limited resources, chronic illnesses, and/or mental health problems. ${ }^{28-30}$

Noting these favorable effects of having a usual source of care (USC), it is surprising to see the continuation of policies and practices that contribute to discontinuity. For some US health plans, negotiating lower-cost contracts is more important than preserving patient-physician continuity. ${ }^{31}$ These shifts in insurance coverage can force a patient to choose a new USC. ${ }^{32}$ In other cases, patients themselves choose to change providers or clinics ${ }^{33}$ or just prefer convenience rather than continuity. ${ }^{34}$

The association between continuity of care and better health outcomes is well established, and much of this literature has informed recent policy efforts to create medical homes. ${ }^{15-20,35,36}$ It is also more common for patients reporting good communication with their physicians to report better health status. ${ }^{3-5}$ Less is known, however, about whether or not patients who have a USC perceive their clinicians to be better communicators and what factors might impact interactions in the setting of a USC. One relevant study conducted to explore multiple factors associated with perceptions about communication suggested that having a USC plays a significant role. ${ }^{3}$ The primary aim of our study was to add further depth to this inquiry by focusing specifically on a USC as the main predictor and by examining the extent to which having a USC influenced the likelihood that patients perceive positive communication and health care interactions. Secondarily, we examined only those respondents with a USC to determine whether certain demographic characteristics were associated with differences in how patients with a USC perceived their involvement in health care decision making.

\section{Methods}

\section{Data Source}

Data used in this cross-sectional study were obtained from the 2002 Medical Expenditure Panel Survey (MEPS) files, sponsored and made available to the public by the Agency for Health Care Research and Quality. ${ }^{25}$ The MEPS consists of a subsample of respondents to the National Health Interview Survey, selected to achieve a nationally representative sample of the civilian, noninstitutionalized population in the United States. ${ }^{37}$ MEPS interviews are conducted 5 times over a 2-year period using computer-assisted personal interviewing techniques for optimal data collection, with greater than a $60 \%$ response rate. Our first analysis was restricted to MEPS participants over the age of 18 who had visited a health care provider in the 12 months immediately before the fielding of the survey ( $\mathrm{n}=\sim 16,700$ ). Our second analysis focused on all adult respondents to MEPS, regardless of a recent visit, who reported having a USC site $(\mathrm{n}=$ $\sim 18,000$ ).

\section{Independent Variables}

In the first analysis, the independent variable of primary interest was whether or not each respondent had a USC. To determine USC, respondents were asked: Is there a particular doctor's office, clinic, health center, or other place that you usually go to if you are sick or need advice about your health? Theoretical models of health services utilization described by Phillips et $\mathrm{al}^{38}$ and Aday and Andersen ${ }^{39,40}$ have outlined patient characteristics and system factors that compromise access to health care for certain populations. Based on these models, demographic covariates included in the multivariate analysis included sex, age, race, ethnicity, family income, high school completion, census region, urban/nonurban residence, and health insurance status. For the second analysis, these demographic covariates were all included as independent variables.

\section{Dependent Variables}

We used a recent theoretical framework describing key attributes of patient preferences for primary care to guide the selection of outcome variables. ${ }^{41}$ From the conceptual map, we chose 2 categories most relevant to health communication: (1) patient preferences about interpersonal care and (2) patient-centeredness. We found 6 related MEPS survey items. Among participants who reported going 
to a doctor's office or clinic in the 12 months before the survey, 4 outcome variables were measured. These questions pertained to how patients perceived their recent health care interactions, including how often their health care providers listened carefully to them, explained things clearly to them, showed respect for what they had to say, and spent enough time with them. In the second analysis, 2 dependent variables were measured among all survey respondents who identified having a USC: (1) If there were a choice between treatments, how often would a provider at your USC ask you to help make the decision? and (2) How often does a provider at your USC give you some control over your treatment? Responses to all 6 survey questions were reported on a 4-point scale (always, usually, sometimes, never). We surmised that a response of "always" would signify optimal health care communication; furthermore, a large majority of respondents reported either always or never. So, for the purposes of creating logistic regression models, the responses were dichotomized into "always" and "not always."

\section{Analytical Strategy}

Initially, descriptive statistics were obtained for the entire MEPS adult population to determine the relationship between demographic covariates and the first predictor variable (having a USC) (Table 1). Then, for the first multivariable analysis, the sample was limited to those MEPS adults who had visited a health care facility in the 12 months preceding the 2002 survey. Descriptive analyses were conducted among this subgroup to determine the relationship between demographic characteristics and the initial 4 outcome variables (patient perceptions of physician communication). A series of logistic regression models were created to determine the strength of associations between the USC predictor variable and the outcome variables, while controlling for several factors (Table 2). Factors selected as covariates for inclusion in the models were guided by conceptual models of health services utilization, and all were found to have significant associations $(P<.05)$ with at least one of the outcomes in $\chi^{2}$ analyses. In the second analysis, limited to participants who reported having a USC, a series of logistic regression models were performed to explore the independent influence of each demographic characteristic-while simultaneously controlling for all of the other covari-
Table 1. Demographic Characteristics of American Adults Who Have a Usual Source of Care

\begin{tabular}{|c|c|c|}
\hline Demographic Characteristics & $\begin{array}{l}\text { Patients with a Usual } \\
\text { Source of Care } \\
\text { (weighted \%)* }\end{array}$ & $P^{\dagger}$ \\
\hline Total Adults in US & 78.3 & \\
\hline \multicolumn{3}{|l|}{ Sex } \\
\hline Male & 73.2 & $<.0001$ \\
\hline Female & 83.0 & \\
\hline \multicolumn{3}{|l|}{ Age (years) } \\
\hline $18-24$ & 65.1 & $<.0001$ \\
\hline $25-44$ & 70.5 & \\
\hline $45-64$ & 85.1 & \\
\hline$\geq 65$ & 94.0 & \\
\hline \multicolumn{3}{|l|}{ Race } \\
\hline White & 79.3 & $<.0001$ \\
\hline Black & 74.3 & \\
\hline American Indian & 74.4 & \\
\hline Asian & 69.9 & \\
\hline Native Hawaiian & 77.5 & \\
\hline Multiple Races & 72.9 & \\
\hline \multicolumn{3}{|l|}{ Ethnicity } \\
\hline Hispanic & 59.9 & $<.0001$ \\
\hline Non-Hispanic & 80.8 & \\
\hline \multicolumn{3}{|l|}{ Family income } \\
\hline Poor & 70.0 & $<.0001$ \\
\hline Near poor & 71.5 & \\
\hline Low income & 72.0 & \\
\hline Middle income & 77.7 & \\
\hline High income & 83.4 & \\
\hline \multicolumn{3}{|l|}{ Completed high school } \\
\hline Yes & 79.5 & $<.0001$ \\
\hline No & 73.2 & \\
\hline \multicolumn{3}{|l|}{ Geographic residence } \\
\hline Northeast & 85.6 & $<.0001$ \\
\hline Midwest & 81.4 & \\
\hline South & 74.9 & \\
\hline West & 74.2 & \\
\hline \multicolumn{3}{|l|}{ Residence location } \\
\hline $\begin{array}{l}\text { Metropolitan atatistical } \\
\text { area }\end{array}$ & 77.5 & $<.001$ \\
\hline $\begin{array}{l}\text { Non-metropolitan } \\
\text { statistical area }\end{array}$ & 81.8 & \\
\hline \multicolumn{3}{|l|}{ Health Insurance } \\
\hline Any private & 82.5 & $<.0001$ \\
\hline Public & 85.8 & \\
\hline Uninsured & 46.7 & \\
\hline
\end{tabular}

Data Source: 2002 Medical Expenditure Panel Survey.

${ }^{*}$ Unweighted $\mathrm{N}=25,851$. Note that percentages have been rounded to nearest tenth.

${ }^{\dagger} P$ in the $\chi^{2}$ analysis for overall differences between subcategories of each demographic characteristic. 
Table 2. Differences in Patient Perceptions about Physician Communication among Patients With and Without a Usual Source of Care

\begin{tabular}{|c|c|c|}
\hline Survey Questions Regarding Physician Communication & $\begin{array}{l}\text { Patients Responding "Always" } \\
\text { to Questions Regarding } \\
\text { Physician Communication } \\
\text { (weighted } \% \pm \mathrm{SE})^{*}\end{array}$ & $\begin{array}{c}\text { Odds of Responding "Always" } \\
\text { to the Key Questions } \\
(\text { Multivariate OR [ } 95 \% \text { CI }])^{\dagger}\end{array}$ \\
\hline \multicolumn{3}{|l|}{ Provider listened carefully to them $(\mathrm{n}=16,699)$} \\
\hline US adults with a USC & $56.4 \pm 0.58$ & $1.31(1.16-1.48)$ \\
\hline US adults without a USC & $47.1 \pm 1.38$ & 1.00 \\
\hline \multicolumn{3}{|l|}{ Provider explained things so they understood $(\mathrm{n}=16,700)$} \\
\hline US adults with a USC & $57.9 \pm 0.59$ & $1.26(1.13-1.41)$ \\
\hline US adults without a USC & $51.3 \pm 1.23$ & 1.00 \\
\hline \multicolumn{3}{|l|}{ Provider showed respect for what they had to say $(\mathrm{n}=16,781)$} \\
\hline US adults with a USC & $59.9 \pm 0.55$ & $1.24(1.10-1.40)$ \\
\hline US adults without a USC & $52.3 \pm 1.34$ & 1.00 \\
\hline \multicolumn{3}{|l|}{ Provider spent enough time with them $(\mathrm{n}=16,773)$} \\
\hline US adults with a USC & $46.7 \pm 0.57$ & $1.20(1.07-1.35)$ \\
\hline US adults without a USC & $39.0 \pm 1.31$ & 1.00 \\
\hline
\end{tabular}

Data Source: 2002 Medical Expenditure Panel Survey.

${ }^{*}$ Weighted percentages pertain to the total civilian, non-institutionalized US adult population who had visited a healthcare provider in the previous 12 months (unweighted $\mathrm{n}$ varies slightly by category, as noted).

${ }^{\dagger}$ Adjusted for sex, age, race, ethnicity, family income, education, geographic region, MSA status, health insurance status.

Statistical significance indicated by bolded values.

ates - on respondents' perceptions of autonomy in health care decision making (Table 3).

SUDAAN software (release 9.0.1, Research Triangle Institute, Research Triangle Park, NC) was used to conduct the statistical tests and to make national estimates with variance adjustments required for the complex sampling design of the 2002 MEPS. In all tables provided, the reported percentages have been weighted to produce estimates for the entire civilian, noninstitutionalized US population.

\section{Results}

\section{Demographics}

More than 78\% of US adults had a USC in 2002. Having a USC was not equally distributed among different demographic subgroups (Table 1). For example, $94 \%$ of people over the age of 64 reported having a USC, compared with only $65.1 \%$ of those between the ages of 18 and 24. A higher percentage of women $(83.0 \%)$ had a USC when compared with their male counterparts $(73.2 \%)$. Less than $75 \%$ of the black respondents reported having a USC, compared with nearly $80 \%$ of the whites. Only $59.9 \%$ of Hispanics reported having a USC, compared with $80.8 \%$ of the non-Hispanics. Adults who had completed high school were more likely to have a USC $(79.5 \%)$ versus those who had not completed high school (73.2\%). Only $70 \%$ of adults in the lowest income group had a USC, compared with nearly $84 \%$ of those with the highest incomes. Among those with insurance, over $82 \%$ with private insurance had a USC whereas fewer than $47 \%$ of the uninsured had a USC.

\section{The Association Between Having a USC and Perceived Positive Communication}

After controlling for the effects of all demographic characteristics reported in Table 1, positive patient perceptions about physician communication were significantly associated with having an identified USC (Table 2). When compared with adults reporting no USC (reference group; odds ratio [OR], 1.00), adults with a USC were more likely to report that their physician always listened to them (OR, 1.31; 95\% CI, 1.16-1.48); always explained things so they could understand (OR, 1.26; 95\% CI, 1.131.41); always showed respect (OR, 1.24; $95 \% \mathrm{CI}$, 1.10-1.40); and always spent enough time with them (OR, 1.20; 95\% CI, 1.07-1.35).

\section{Patient Perceptions about Their Involvement in Health Care Decision-Making}

Among all respondents with a USC there were demographic differences between how respondents 
Table 3. Demographic Characteristics of Those with a Usual Source of Care and Their Perceptions About Their Degree of Health Decision-Making Autonomy

\begin{tabular}{|c|c|c|c|c|}
\hline \multirow[t]{2}{*}{ Demographic Characteristics } & \multicolumn{2}{|c|}{$\begin{array}{c}\text { Provider "Always" Gives Person Control of } \\
\text { Treatment }(\mathrm{n}=18,087)\end{array}$} & \multicolumn{2}{|c|}{$\begin{array}{c}\text { Provider "Always" Asks Person to Help Make } \\
\text { Health Care Decisions }(n=17,674)\end{array}$} \\
\hline & Weighted \%* & Multivariate OR (95\% CI) & Weighted \%* & Multivariate OR (95\% CI) \\
\hline Total & 50.1 & & 52.2 & \\
\hline \multicolumn{5}{|l|}{ Sex } \\
\hline Male & 49.7 & $0.95(0.91-1.00)$ & 51.8 & $0.95(0.89-1.00)$ \\
\hline Female & 50.4 & 1.00 & 52.6 & 1.00 \\
\hline \multicolumn{5}{|l|}{ Age (years) } \\
\hline $18-24$ & 48.0 & $0.88(0.74-1.04)$ & 48.0 & $0.78(0.66-0.92)$ \\
\hline $25-44$ & 50.9 & $0.92(0.81-1.03)$ & 50.9 & $0.85(0.75-0.96)$ \\
\hline $45-64$ & 53.5 & $0.99(0.87-1.13)$ & 53.5 & $0.91(0.80-1.03)$ \\
\hline$\geq 65$ & 54.7 & 1.00 & 54.7 & 1.00 \\
\hline \multicolumn{5}{|l|}{ Race } \\
\hline White & 51.1 & $1.56(1.09-2.23)$ & 53.2 & $1.39(0.96-2.01)$ \\
\hline Black & 47.1 & $1.37(0.95-1.96)$ & 50.4 & $1.28(0.87-1.89)$ \\
\hline American Indian & 46.6 & $1.36(0.80-2.33)$ & 46.2 & $1.09(0.63-1.88)$ \\
\hline Asian & 39.0 & $1.04(0.66-1.65)$ & 41.0 & $0.95(0.59-1.53)$ \\
\hline Native Hawaiian & 37.2 & $0.98(0.36-2.63)$ & 36.1 & $0.77(0.29-2.02)$ \\
\hline Multiple Races & 38.5 & 1.00 & 43.2 & 1.00 \\
\hline \multicolumn{5}{|l|}{ Ethnicity } \\
\hline Hispanic & 42.6 & $0.83(0.72-0.95)$ & 46.0 & $0.88(0.76-1.01)$ \\
\hline Black/non-Hispanic & 50.8 & 1.00 & 52.9 & 1.00 \\
\hline \multicolumn{5}{|l|}{ Family income } \\
\hline Poor & 43.7 & $0.80(0.69-0.93)$ & 46.9 & $0.84(0.72-0.98)$ \\
\hline Near poor & 54.2 & $1.17(0.94-1.47)$ & 56.4 & $1.16(0.93-1.45)$ \\
\hline Low income & 47.8 & $0.88(0.77-1.01)$ & 50.4 & $0.90(0.78-1.04)$ \\
\hline Middle income & 48.8 & $0.87(0.79-0.97)$ & 51.5 & $0.90(0.81-1.00)$ \\
\hline High income & 52.6 & 1.00 & 54.1 & 1.00 \\
\hline \multicolumn{5}{|l|}{ Completed high school } \\
\hline Yes & 51.0 & $1.09(0.98-1.21)$ & 52.9 & $1.06(0.95-1.18)$ \\
\hline No & 46.0 & 1.00 & 49.3 & 1.00 \\
\hline \multicolumn{5}{|l|}{ Census region } \\
\hline Northeast & 53.4 & $1.41(1.17-1.70)$ & 54.7 & $1.36(1.14-1.62)$ \\
\hline Midwest & 50.7 & $1.21(1.01-1.43)$ & 52.8 & $1.20(1.02-1.42)$ \\
\hline South & 51.5 & $1.29(1.07-1.55)$ & 54.2 & $1.30(1.09-1.55)$ \\
\hline West & 43.7 & 1.00 & 46.0 & 1.00 \\
\hline \multicolumn{5}{|l|}{ Urban/rural } \\
\hline MSA & 49.9 & $0.81(0.68-0.96)$ & 51.1 & $0.81(0.68-0.96)$ \\
\hline Non-MSA & 54.6 & 1.00 & 56.9 & 1.00 \\
\hline \multicolumn{5}{|l|}{ Health insurance } \\
\hline Any private & 51.4 & $1.16(1.02-1.32)$ & 53.4 & $1.16(1.01-1.34)$ \\
\hline Public & 45.4 & $0.98(0.83-1.17)$ & 48.7 & $0.99(0.84-1.16)$ \\
\hline Uninsured & 46.0 & 1.00 & 48.0 & 1.00 \\
\hline
\end{tabular}

Data Source: 2002 Medical Expenditure Panel Survey.

${ }^{*}$ Weighted percentages pertain to the total civilian, non-institutionalized US adult population who reported having a USC in 2002. Statistical significance indicated by bolded values.

OR, odds ratio; CI, confidence interval; MSA, metropolitan statistical area.

perceived their involvement in health care decision making (Table 3). For example, respondents who reported that their providers always gave them con- trol over treatment choices were more likely to be white as compared with other races. Ethnicity was also significant; Hispanics perceived that providers 
gave them less control over treatment decisions. This association with ethnicity is in contrast to the higher likelihood of Hispanic respondents in the overall population reporting positive communication with their providers (Table 3). Although no significant differences were seen between age groups when responding to the question about having control over treatments, the younger respondents (18 to 44 years of age) were less likely to report that their providers asked them to help make decisions.

In response to both questions about health care decision making, patients living in households with the lowest family incomes were least likely to report that their providers offered autonomy in health care decision making. When considering location of geographic residence, respondents living in the West and/or living in a metropolitan statistical area were less likely to be given control over treatments or to be asked to help make decisions. Having private insurance was associated with a higher likelihood of reporting autonomy in making decisions about one's own health care (Table 3).

\section{Discussion}

These findings confirm the importance of having a USC and add further depth to the discussion about how a USC fits into the communication equation. As shown in Table 3 and reported elsewhere, ${ }^{3}$ having a USC was associated with a higher likelihood that a patient will report positive health care communication. It is unclear whether this finding suggests that patients tend to stay with practices that have clinicians who are better communicators, or if having access to a consistent USC actually improves communication over time. Most likely, it is a combination of both explanations.

Given the crucial role of communication in successful health care delivery, ${ }^{42}$ what can be done to help patients without a USC? As shown in Table 1, access to a USC is not randomly distributed among all patients. Efforts aimed at ensuring that more people have a USC should target populations who have historically been left without reliable access to health care services. These findings call for targeted expansions in the US primary care workforce and improvements in the fragile safety net to provide a secure USC to more underserved populations. ${ }^{43-48}$ Family physicians must play a crucial role in expanding the availability of patient-centered medical homes and strengthening the comprehensiveness and consistency of this crucial first point of access to the health care system. ${ }^{35,36,49}$

Once a USC is more widely available, continuity relationships can be more easily established and their many outcomes benefits achieved. ${ }^{15-20}$ In addition, continuity should be prioritized over profit maximization, and patients should always be involved in the decision to switch providers. ${ }^{50} \mathrm{Al}$ though many of the insurance complexities may be unique to the United States, continued efforts to bolster the primary care workforce across the globe are essential to ensuring that access will be readily available to everyone.

However, simply having a place to go for usual care is often not enough. Access to a USC is not a guarantor of active patient involvement in health care decision making, nor does it assure provision to buy prescriptions, to access specialty care, to obtain certain needed procedures, or to receive home care services. ${ }^{47}$ The second crucial aspect that requires further attention, simultaneously with efforts to ensure that every patient has a medical home, is to ensure equity in how care is delivered to an extremely diverse US population.

This study highlights disparities not only in the distribution of USCs across the population but also in how patients from different backgrounds with an identified USC perceived being involved in making their own health care decisions. For example, fewer Hispanics reported having a USC as compared with non-Hispanics, and those with a USC were less likely to report that a provider always gave them control over treatment decisions. This disparity may be because of unequal access to a USC based on race and ethnicity, but it may also be because of how Hispanic patients interpreted the survey questions or the fact that they may have different expectations about how to become involved in making health care decisions. ${ }^{51}$ There is also variation in how a USC is defined and utilized by patients from different backgrounds. In addition, some patients may consider a specialty office or a nearby urgent care center to be their USC, where the quality of communication and involvement of patients in health care decision making is substantially different from a primary care physician's office. This situation may disproportionately affect racial/ethnic minorities and/or people from some certain demographic groups and provide an explanation for some of our observed disparities. 
What can be done to help everyone consistently report being included in the decisions being made about their health care? Regardless of having a USC, insurance coverage plays a major role in how health care decisions get made in the United States. ${ }^{52}$ Any policies that would improve access to a USC for patients living in the United States must also take into account the effects of insurance status.

More globally, eliminating disparities in the way care is provided and received will involve paying closer attention to other factors that impact the receipt of services and patient involvement in health care decision making. ${ }^{43,53-55}$ Based on findings from this study, further work needs to focus on ways to improve patient-physician communication and patient involvement in making treatment decisions, especially among racial/ethnic minorities and younger patients. In addition, steps need to be taken to facilitate an increased role for patients from lower socioeconomic groups and urban areas in their own health care decision making.

In addition to policy change, these efforts need to be targeted at the point where care is delivered. ${ }^{42,56}$ As primary care physicians in the United States move to build medical homes, an awareness of these specific disparities will be useful in the design of interventions that can be incorporated into demonstration programs. We must also expand programs that teach medical students and residents important communication skills as integral components in the improved training of future generations. These skills include how to identify patients who fit into populations less likely to be given decision making autonomy and how to elicit patient communication preferences to improve shared decision making. ${ }^{1,57}$

Medical students, residents, and practicing physicians should be taught to be cognizant of the health literacy skills of their patient populations. Of note, more than half of American adults lack the health literacy skills needed to adequately navigate their way through the complex health care system. ${ }^{58}$ Health literacy screening tools, such as the Rapid Estimate of Adult Literacy in Medicine and Newest Vital Sign, can be used rather quickly to measure patients' health literacy skills and provide physicians needed information to tailor messages appropriately to each patient. ${ }^{59-61}$ Lastly, strategies such as the "Teach Back" or "Show Me" techniques, in which the patient describes in his/her own words what was discussed during the clinical encounter, can be effective in verifying patient understanding. ${ }^{62-64}$ Ultimately, having a USC will help to foster improved communication between physicians and patients, in particular those with limited health literacy skills.

\section{Limitations}

There are important limiting factors to consider in the interpretation of this study analysis. As in all surveys, MEPS responses are subject to possible reporting error and response bias not accounted for by statistical adjustments. Our findings are associations between variables and do not establish causal relationships. This study uses secondary analysis of existing data; therefore, it is limited by the questions included on the MEPS. For example, the MEPS survey asks about a USC site and not a personal physician or continuity provider. We were also unable to capture the "culture" of caring at various USC sites, ie, capture differences between a primary care medical home versus an urgent care center. Although this study was not able to define the outcome as a continuity relationship with a personal physician or to select only qualifying USC sites based on a narrow set of inclusion criteria, just finding a USC is an essential first step toward building a continuity relationship with one or more clinicians.

Finally, the adjusted odds ratios show that patients with a USC are only $20 \%$ to $31 \%$ more likely to report positive perceptions of their provider's communication style as compared with patients without a USC. Although these numbers seem to suggest a fairly small effect size, it is important to remember that the large MEPS sample size does allow for precision of estimates (demonstrated by the small standard errors reported in Table 2). Even among the smaller group without a USC, standard error is less than $1.5 \%$, and there is no overlap between the reported percentages between the 2 groups. ${ }^{65}$ As with any statistically significant findings, these numbers must be further scrutinized in a broader context to determine whether they are clinically relevant.

\section{Conclusions}

This study suggests that one way to improve communication in health care settings is to develop policies and practices to ensure that all patients 
have consistent access to a USC. Once this relationship is established, further work can be done to eliminate disparities in the way care is provided and received. In addition to changing national policies to ensure access to a USC, educational programs need to target individual practices to increase awareness among clinicians about how to actively involve all patients participation, to the extent that they desire, in decisions about their health.

The authors wish to acknowledge Dr. Robert Phillips, Director of the Robert Graham Center, for providing ideas and facility support for the project.

\section{References}

1. Schwartzberg JG, VanGest JB, Wang CC, editors. Understanding Health Literacy. Chicago (IL): American Medical Association; 2005.

2. Duberstein P, Meldrum S, Fiscella K, Shields CG, Epstein RM. Influences on patients' ratings of physicians: physicians demographics and personality. Patient Educ Couns 2006;65:270-4.

3. Rutten LJ, Augustson E, Wanke K. Factors associated with patients' perceptions of health care providers' communication behavior. J Health Commun 2006;11(Suppl 1):35-46.

4. Griffin SJ, Kinmonth AL, Veltman MW, Gillard S, Grant J, Stewart M. Effect of health-related outcomes of interventions to alter the interaction between patients and practitioners: a systematic review of trials. Ann Fam Med 2004;2:595-608.

5. Beach MC, Keruly J, Moore RD. Is the quality of the patient-provider relationship associated with better adherence and health outcomes for patients with HIV? J Gen Intern Med 2006;21:661-5.

6. Sisk J, Gorman S, Reisinger A, Gilied S, DuMouchel W, Hynes M. Evaluation of Medicaid managed care: satisfaction, access, and use. JAMA 1996;276:50-5.

7. Wasson J, Sauvigne A, Mogielnicki P. Continuity of outpatient medical care in elderly men. JAMA 1984; 252:2413-7.

8. Gill J. Can hospitalizations be avoided by having a regular source of care? Fam Med 1996;29:166-71.

9. Gill J, Diamond J. Effect of primary care on emergency department use: evaluation of a statewide Medicaid program. Fam Med 1996;28:178-82.

10. Grumbach K, Keane D, Bindman AB. Primary care and public emergency department overcrowding. Am J Pub Health 1993;83:372-8.

11. Sarver JH, Cydulka RK, Baker DW. Usual source of care and nonurgent emergency department use. Acad Emerg Med 2002;9:916-23.

12. DeVoe J, Fryer G, Phillips R, Green L. Receipt of preventive care among adults: insurance status and usual source of care. Am J Pub Health 2003;93:78691.
13. Doescher MP, Saver BG, Fiscella K, Franks P. Preventive care: does continuity count? J Gen Intern Med 2004;19:632-7.

14. Parchman ML, Burge SK. The patient-physician relationship, primary care attributes, and preventive services. Fam Med 2003;36:22-7.

15. DiMatteo MR, Sherbourne CD, Hays RD, et al. Physicians' characteristics influence patients' adherence to medical treatment: results from the Medical Outcomes Study. Health Psychol 1993;12:93-102.

16. Garrity TF, Haynes RB, Mattson ME, Engebretson $\mathrm{Jr}$ TO. Medical compliance and the clinical-patient relationship: a review. Washington DC: National Institutes of Health; 1998.

17. Ren XS, Kazis LE, Lee A, Zhang H, Miller DR. Identifying patient and physician characteristics that affect compliance with antihypertensive medications. J Clni Pharm Ther 2002;27:47-56.

18. Linn MW, Linn BS, Stein SR. Satisfaction with ambulatory care and compliance in older patients. Med Care 1982;20:606-14.

19. Saultz JW, Albedaiwi W. Interpersonal continuity of care and patient satisfaction: a critical review. Ann Fam Med 2004;2:445-51.

20. Mainous AG, Baker R, Love MM, Gray DP, Gill JM. Continuity of care and trust in one's physician: evidence from primary care in the United States and the United Kingdom. Fam Med 2001;33:22-7.

21. Hayward R, Bernard A, Freeman H, Corey C. Regular source of ambulatory care and access to health services. Am J Pub Health 1991;81:434-8.

22. Weissman JS, Stern RS, Fielding SL, Epstein AM. Delayed access to health care: risk factors, reasons, consequences. Ann Intern Med 1991;144:325-31.

23. Saver BG, Peterfreund N. Insurance, income, and access to ambulatory care in King County, Washington. Am J Pub Health 1993;83:1583-8.

24. Baker DW, Stevens CD, Brooks RH. Regular source of ambulatory care and medical care utilization by patients presenting to a public hospital emergency department. JAMA 1994;1994:1909-12.

25. Weinick RM, Zuvekas SH, Drilea SK. Access to health care: source and barriers, 1996. MEPS Research Findings No. 3, AHCPR Pub. No. 98 to 0001. Rockville (MD): Agency for Health Care Policy and Research; 1997.

26. Centers for Disease Control. Demographic characteristics of persons without a regular source of care: selected states, 1995. MMWR Morb Mortal Wkly Rep 1995;47:277-9.

27. Shea S, Misra D, Ehrilick MH, Field L, Francis CK. Predisposing factors for severe uncontrolled hypertension in an inner-city minority population. N Engl J Med 1992;327:1085-90.

28. Franks P, Clancy CM, Nutting PA. Gatekeeping revisited-protecting patients from overtreatment. N Engl J Med 1992;327:424-7. 
29. Stange KC, Jaen CR, Flock SA, Miller WL, Crabtree BF, Zyzanski SJ. The value of a family physician. J Fam Pract 1998;46:363-8.

30. Nutting PA, Goodwin MA, Flocke SA, Zyzanski SJ, Stange KC. Continuity of primary care: to whom does it matter and when? Ann Fam Med 2003;1: 149-55.

31. Emanuel EJ, Dubler NN. Preserving the patientphysician relationship in the era of managed care. JAMA 1995;273:323-9.

32. Flocke SA, Stange KC, Zyzanski SJ. The impact of insurance type and forced discontinuity on the delivery of primary care. J Fam Pract 1997;45:129-35.

33. Safran DG, Montgomery JE, Chang H, Murphy J, Rogers WH. Switching doctors: predictors of voluntary disenrollment from a primary physician's practice. J Fam Pract 2001;50:130-6.

34. Viera AJ, Pathman DE, Garrett JM. Adults' lack of a usual source of care: a matter of preference? Ann Fam Med 2006;4:359-65.

35. American Academy of Family Physicians, American Academy of Pediatrics, American College of Physicians, American Osteopathic Association. Joint Principles of the Patient-Centered Medical Home; 2007. Available at http://www.pcpcc.net/content/jointprinciples-patient-centered-medical-home. Accessed June 1, 2008.

36. Grumbach K, Bodenheimer T. A primary care home for Americans: putting the house in order. JAMA 2002;288:889-93.

37. Zuvekas SM, Weinick RM. Changes in access to care, 1977 to 1996: the role of health insurance. Health Serv Res 1999;34(1 Pt 2):271-9.

38. Phillips K, Morrison K, Andersen R, Aday L. Understanding the context of health care utilization: assessing environmental and provider-related variables in the behavioral model of utilization. Health Serv Res 1998;33:571-96.

39. Aday LA, Andersen R. A framework for the study of access to medical care. Health Serv Res 1974;9:20820.

40. Andersen R. Revisiting the behavioral model and access to medical care: does it matter? J Health Soc Behav 1995;36:1-10.

41. Cheraghi-Sohi S, Bower P, Mead N, McDonald R, Whalley D, Roland M. What are the key attributes of primary care for patients? Building a conceptual 'map' of patient preferences. Health Expect 2006;9: 275-84.

42. Flynn KE, Smith MA, Vanness D. A typology of preferences for participation in health care decision making. Soc Sci Med 2006;63:1158-69.

43. Cunningham PJ. A changing picture of uncompensated care. Health Aff 1997;16:167-75.

44. Cunningham PJ. Pressures on the health care safety net: implications for access to care for the uninsured. Health Serv Res 1999;34:255-70.
45. Cunningham PJ, Grossman JM, Peter RFS, Lesser CS. Managed care and physicians' provision of charity care. JAMA 1999;281:1087-92.

46. Institute of Medicine. America's health care safety net: intact but endangered. Washington DC: Institute of Medicine; 2000.

47. Weiss E, Haslanger K, Cantor J. Accessibility of primary care services in safety net clinics in New York City. Am J Pub Health 2001;91:1240-45.

48. Shi L, Starfield B. The effect of primary care physician supply and income inequality on mortality among blacks and whites in US metropolitan areas. Am J Pub Health 2001;91:1246-50.

49. Martin JC, Avant RF, Bowman MA, et al. The Future of Family Medicine: a collaborative project of the family medicine community. Ann Fam Med 2004;2:S3-S32.

50. Cunningham PJ, Kohn L. Health plan switching: choice or circumstance? Health Aff 2000;19:158-64.

51. Wallace L, DeVoe J, Rogers E, Malagon-Rogers M, Fryer G. The medical dialogue: disentangling differences between Hispanic and non-Hispanic whites. J Gen Intern Med 2007;22:1538-43.

52. Meyer DS, Mishori R, McCann J, Delgado J, O'Malley AS, Fryer GE. Primary care physicians' perceptions of the effect of insurance status on clinical decision making Ann Fam Med 2006;4:399402.

53. Cunningham PJ, Kemper P. Ability to obtain medical care for the uninsured. JAMA 1998;280:921-7.

54. Cunningham PJ, Kemper P. The uninsured getting care: where you live matters. Issue Brief \#15. Washington DC: Center for Studying Health System Change; 1998.

55. Cunningham PJ, Whitmore HH. How well do communities perform on access to care for the uninsured? Research Report \#1. Washington DC: Center for Studying Health System Change; 1998.

56. Beach MC, Roter DL, Wang NY, Duggan PS, Cooper LA. Are physicians' attitudes of respect accurately perceived by patients and associated with more positive communication behaviors? Patient Educ Couns 2006;62:347-54.

57. Swenson SL, Zettler P, Lo B. "She gave it her best shot right away": patient experiences of biomedical and patient-centered communication. Patient Educ Couns 2006;61:200-11.

58. National Center for Education Statistics. National assessment of adult literacy: a first look at the literacy of America's adults in the 21st century. NCES Publication No. 2006470. Washington DC: National Center for Education Statistics; 2005.

59. Davis T, Long S, Jackson R, et al. Rapid estimate of adult literacy in medicine: a shortened screening instrument. Fam Med 1993;25:391-5.

60. Weiss B, Mays M, Martz W, et al. Quick assessment of literacy in primary care: the newest vital sign. Ann Fam Med 2005;3:514-22. 
61. Weiss B. Health literacy: a manual for clinicians. Chicago (IL): American Medical Association Foundation; 2003.

62. Wilson F, Baker LM, Nordstrom CK, Legwand C. Using the teach-back and Orem's Self-care Deficit Nursing theory to increase childhood immunization communication among low-income mothers. Issues Compr Pediatr Nurs 2008;31:7-22.

63. Schillinger D, Piette J, Grumbach K, et al. Closing the loop: physician communication with diabetic pa- tients who have low health literacy. Arch Intern Med 2003;163:83-90.

64. Kemp C, Floyd MR, McCord-Duncan E, Lang F. Patients prefer the method of "tell back-collaborative inquiry" to assess understanding of medical information. J Am Board Fam Med 2008;21:2430.

65. Cohen J. Statistical power analysis for the behavioral sciences, 2nd ed. Hillsdale (NJ): Lawrence Earlbaum Associates; 1988. 